\title{
Siliconized Graphite Production Technology
}

\author{
SkakovM.K. \\ National Nuclear Center \\ RSE NNC RK \\ Kurchatov, Kazakhstan \\ e-mail: skakov@nnc.kz \\ Kurbanbekov Sh.R.
Branch Institute of Atomic Energy RSE NNC RK
Kurchatov, Kazakhstan
e-mail: kurbanbekov@nnc.kz \\ Koyanbaev Y.T. \\ Branch Institute of Atomic Energy \\ RSE NNC RK \\ Kurchatov, Kazakhstan \\ e-mail: erbol@nnc.kz
}

\author{
Baklanov V.V. \\ Branch Institute of Atomic Energy \\ RSE NNC RK \\ Kurchatov, Kazakhstan \\ e-mail: baklanov@nnc.kz
}

Miniyazov A. Zh.

Branch Institute of Atomic EnergyRSE NNC RK

Kurchatov, Kazakhstan

e-mail: miniyazov@nnc.kz

\author{
Mukhamedzhanova R.M. \\ Branch Institute of Atomic Energy \\ RSE NNC RK \\ Kurchatov, Kazakhstan \\ e-mail: mukhamedjanova@nnc.kz
}

\begin{abstract}
Present paper is devoted to the development of siliconized graphite production technology. Confirmed that the cheapest and most promising material for the manufacture of siliconized graphite is a natural raw materials (technical carbon black, graphite and quartz). The study experimentally determined value for the specific components and their granulometric parameters that allow to obtain a material with the desired physic mechanical characteristics and physicochemical properties.
\end{abstract}

Keywords-siliconized graphite production, sintering, heat.

\section{INTRODUCTION}

Recently, due to the tightening of working conditions (high temperatures, high pressures, aggressive media) significantly increased requirements for structural materials for their heat resistance and corrosion resistance when exposed to a variety of corrosive media, as well as their durability. Siliconized graphite productslargely meet such requirements. It is heat proof and has good resistance to thermal cycles, wear resistant and can operate continuously in contact with many corrosive liquids and vapors, both at room and at high temperature [1-3].

As a rule, special carbon graphite materials and fired materials are used for siliconizing. . Industrial environments produce siliconized graphite SG-M, SH-T SG-P et al., as well as boron-doped graphite. Table 1 presents an assessment of some of the properties of siliconized graphite, produced in different countries. [5].

Siliconized graphite is a three-phase material comprising carbon, silicon carbide and unreacted or free silicon. In some cases, there may be more or less additive, as well as its carbides and silicides intended for improving the physic mechanical or physical-chemical characteristics depending upon the particular use of the material [4].

A common technology for obtaining siliconized graphite consists essentially of volume impregnation of carbon raw stock obtained by machining or molding, liquid silicon or silicon-based alloys in a vacuum at temperatures 2123-2373 K [5].

It is also well known pressing technology followed by its sintering wherein to produce siliconizedrefractory products they use a mixture comprising graphite (3-35\% wt.), Silicon (3,0-12,5\% wt.), Silicon carbide (1.5 -40\% wt.), coke $(20-30 \%$ wt.), phenolic resins, etc. Siliconized graphite obtained by using said composition has a sufficiently large proportion of the carbon component, due to poor siliconizingof a coke, and in this connection a substantial proportion of free (unreacted) silicon, that is exacerbated in the early introduction of free silicon in reference composition of. Significant amount of free silicon in final material (25-30\% wt.), when iys using, for example, as protective cladding plates, can lead to evaporation of silicon due to high vapor pressure of silicon, i.e. to the appearance of porosity of the material and reducing its strength. It is like contact with aggressive melts, such as water glass or basalt [6].

The study is aimed at the development of low-cost siliconized graphite production technology using cheap natural raw materials: technical carbon black, graphite and quartz. 
Table 1. Different brands of siliconized graphite.

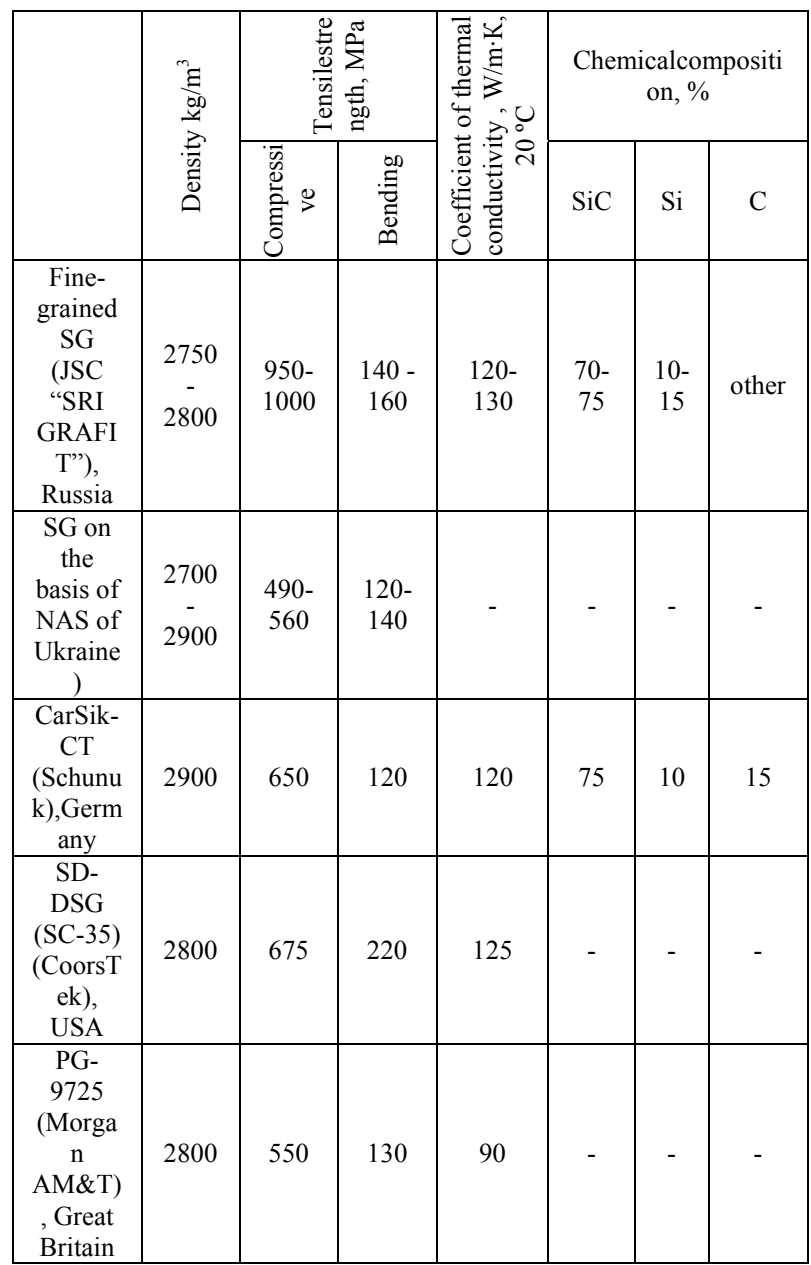

II. MATERIALS AND RESEARCH METHODS

As starting materials to produce siliconized graphite we've used carbon black (soot) GOST 7885-86 and quartz sand GOST 22551-77.

The proposed technology for production of siliconized graphite includes the following main stages: preparation of raw materials (grinding, blending components), pressing and sintering. These operations are performed using the following equipment: a vibrating table FRITSCH to install consistently ball mill of corundum and a set of screens for automatic screening of particles and laboratory hydraulic press $300-800-4 E$. Sintering is carried out in a graphite crucible in a universal high-frequency induction heating stand VCG-135.

Choice of temperature conditions for given technologyis performed by calculation in the analysis of well-known reduction reactions of silicon oxide with carbon:

$$
\mathrm{SiO}_{2}+2 \mathrm{C} \rightarrow \mathrm{Si}+2 \mathrm{CO}
$$

According to [7] and [8] change the Gibbs thermodynamic potential can be calculated by the equation:

$$
\Delta G_{T}^{0}=697390-359,07 \mathrm{~T},
$$

where $\Delta G_{T}^{0}=0$, a $\mathrm{K}_{\mathrm{p}}=1$ at $1943 \mathrm{~K}\left(1670^{\circ} \mathrm{C}\right)$.

This means that, theoretically, the temperature $1670 \mathrm{C}$ is required to start deoxidizing silica with solid carbon by the reaction (1) .

Additionally, electrothermalmethod to produce silicon is well known in the form of its compound with carbon (silicon carbide) by reducing silicon oxide with carbon in high-power electric furnaces [9].

This method intends that the burden for producing silicon carbide consists of a mixture of silicon oxide as quartz sand and petroleum coke. Recovery of silicon oxide with coke carbon is carried out at temperatures of 2200$2500{ }^{\circ} \mathrm{C}$, wherein the oven heating element is a core made of a lumpy carbonaceous material. When recovering $\mathrm{SiO}_{2}$ with carbon, silicon carbide as the desired productis formedin solid form by the reaction:

$$
\begin{aligned}
& \mathrm{SiO}_{2}+3 \mathrm{C} \rightarrow \mathrm{SiC}+2 \mathrm{CO} \\
& \Delta G_{T}^{0}=555615-322,11 \mathrm{~T} \text { кал, }
\end{aligned}
$$

from here $\Delta G_{T}^{0}=0$, a $\mathrm{K}_{\mathrm{p}}=1$ at $1725 \mathrm{~K}\left(1452^{\circ} \mathrm{C}\right)$.

Thus, the method for producing siliconizedgraphite as silicon carbide requires high temperature for the process that can be achieved in an induction crucible furnace, such as induction heating stand VCG-135.

VCG-135 test bench designed on a basis of highfrequencyelectric-bulbgenerator and sealed water-cooled working chamber with an inductor is intended for various high-temperature materials research on small-sized samples. The stand is used for rapid heating of any small samples to the high temperature followed by cooling due to heat losses into a water-cooled inductor while generator is switched off.

Figure 1 shows general view of VCG-135 induction heating test bench.

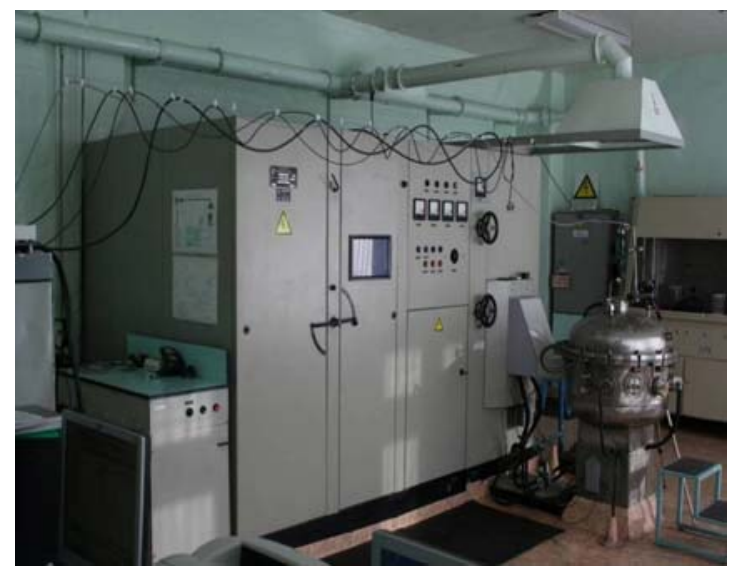

Figure 1. - VCG-135 induction heating test bench

VCG-135 Specifications:

- GeneratorFrequency, kHz66;

- inner diameter of working chamber, mm600;

- height of working chamber, mm700;

- size of inductor, mm $\varnothing 80 \times 150, \varnothing 120 \times 150$;

- temperature sensors ... thermocouples, pyrometers;

- gas atmosphere in working chamber... vacuum, argon; 
- Mass of loaded charge, g100-200.

VCG-135 provides an opportunity to take video during heating and cooling the sample through a viewing window in the lid of the working chamber, as well as the possibility of a gas sampling during the experiment. The temperature is monitored by thermocouples and pyrometers. The main means of temperature measurement are tungsten-rhenium thermocouples WR5/20, with the range of temperature measurementof $1000-2500^{\circ} \mathrm{C}$. These thermocouples measure the temperature on the wall and in the center of the experimental crucible assembly (see Fig. 2).

Also, in the course of the experiment contactless temperature is measured using pyrometers of two types: spectral-ratio pyrometer MIKRON M770S and pyrometer with built-in high-temperature camera IMPAC 140.

Burden is prepared in two stages. Milling of powders to dispersion less than $50 \mathrm{mcm}$ that controlled by sieving when particles pass through sieve meshes of appropriate size. Sample of prepared powders in predetermined proportions are also wear out in a ball mill for $30 \mathrm{~min}$. The resulting mixture is molded in a special mold made of carbon steel with a force of $7,8 \mathrm{MPa}$ at $180^{\circ} \mathrm{C}$ for $30-35$ minutes to obtain a test specimen of $15 \mathrm{~mm}$ diameter and $9 \mathrm{~mm}$ thick. Further, the resulting cylindrical samples, for the acquisition of the final technological properties, are subjected to sintering process.

Samples are placed into a graphite crucible, where graphite distancing plates are installed between the samples. . The obtained experimental assembly is placed in the working chamber of VCG-135 after which the chamber is evacuated by mechanical backing pump NVR-5 to a pressure of $10^{-3} \mathrm{~Pa}$ and is filled with an inert gas (argon) to normal pressure. Schematic of the experimental assembly of the crucible is shown in Fig. 2.

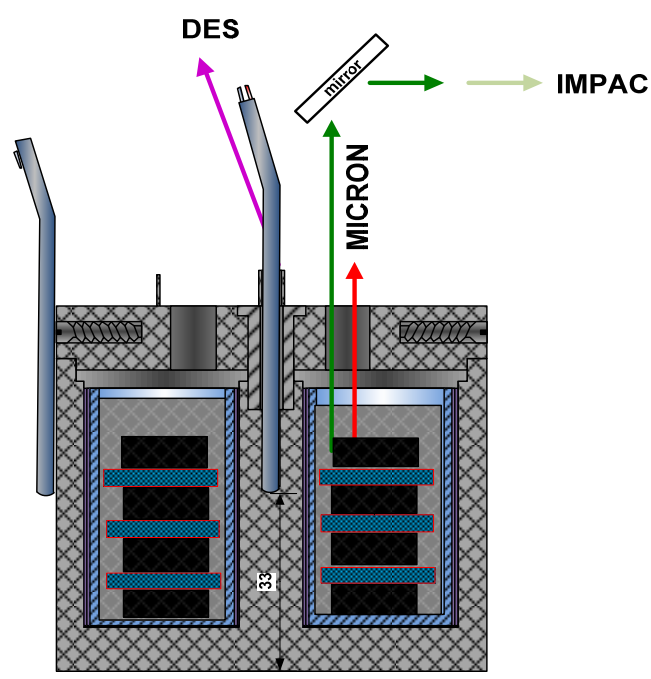

Figure 2. - Experimentalassembly

The procedure of the experiment on samples sintering includes two thermal processing from room temperature to $800^{\circ} \mathrm{C}$ with exposure for 30 minutes and subsequent heating to $1580-1600 \mathrm{C}$ with exposure for $110-120 \mathrm{~min}$.

Diagram of the heating process during sintering shown in Fig. 3

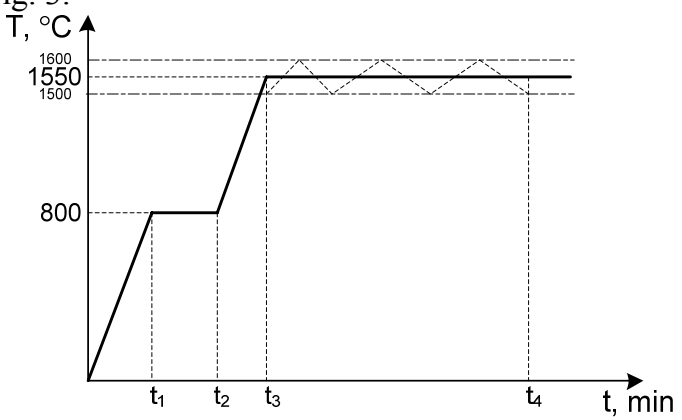

Figure 3. - Diagram of the heating process

The experiment was terminated after natural cooling the assembly up to room temperature. The end result of this processis obtaining a material with a three-phase composition containing silicon carbide, carbon and free silicon.

The sample produced using described technology is shown in Fig. 4.
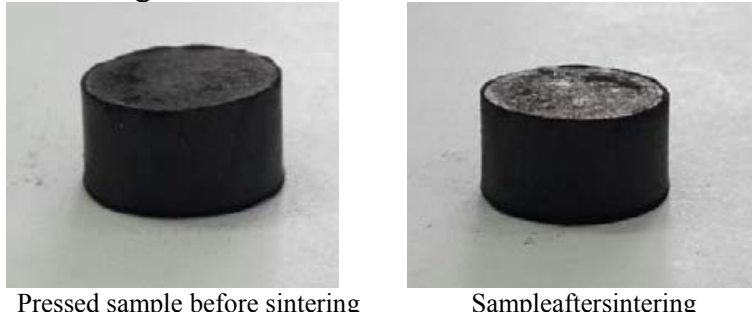

Sampleaftersintering

Figure 4. -General view of the sample undergone all production procedures according to the technology developed

\section{CONCLUSIONS}

The technology to produce siliconized graphite from broadly natural raw materials: carbon black (soot), graphite and silica sandhas been developed, justified and approved in the course of this work. . The proposed technology is effective in obtaining a low-cost material. Further development, improvement and application of this technology makes it possible to produce siliconized graphite not inferior to the properties of many well-known global peers.

\section{REFERENCES}

[1] TarabanovA.S., KostikovV.I. Siliconizedgraphite. M., Matallurgy, 1977. - p. 206

[2] N.R. Calderon, M. Martínez-Escandell, J. Narciso, F. RodriguezReinoso, The combined effect of porosity and reactivity of the carbon preforms on the properties of $\mathrm{SiC}$ produced by reactive infiltration with liquid Si, CARBON, Vol. 47, 2009, pp. 2200-2210

[3] 3.A.N. Seleznev. Carbon raw material for electrode industry. M. Profizdat.: 2000, p. 256 p.

[4] O. Yu. Sorokin, I.A. Bubnenkov, Yu.I. Koshelev, T.V. Orekhov. Development of fine-granular siliconized graphite with improved 
properties.Chemistry and Chemical Engineering 2012.Volume 55. Edition 6, pp 12-16.

[5] A.F.Ilyushchenko, Ye.V. Zvonarev, V.A. OsipovI.V. Fomikhina. On the question of obtaining siliconized graphite and silicon carbide ceramics of engineering purpose "Powder Metallurgy: surface engineering, new powder composite materials. Welding".April 10-12, 2013, Minsk, Belarus,pp.441-445

[6] Patent RU2370435, C2. Carbonaceous composition for siliconized products/ V.I. Kostikov, L.N. Smirnov, O.S. Skibnevskaya (RU).Applied 20.05.2009; published on 20.10.2009
[7] O.M.Katkov Smelting of technical silicon. Irkutsk: EdditionIPU, 1997, p. 243.

[8] N.V. Tolstoguzov. Theoretical bases and technology fusion of siliceous and manganese alloys. M.: Metallurgy, 1992, p. 239.

[9] S.K. Brantov, N.N.Kuznetsov Electro-physical properties of composite materials based on siliconizedcarbon and graphite material // Materials. - 2002. No.5. - pp. 25-27. 